\title{
Spillover effects of children's political status on elderly parents' health in China
}

\author{
Xin Zhao, ${ }^{1}$ Yi Zhou, ${ }^{2}$ Huaqing Tan, ${ }^{3}$ Haoxiang Lin ${ }^{4,5,6,7}$
}

'Department of Laboratory Medicine, Beijing Hospital,

National Center of Gerontology, Beijing, P. R. China

${ }^{2}$ Center for Social Research, Peking University, Beijing, P. R. China

${ }^{3}$ Guanghua School of

Management, Peking University, Beijing, P. R. China

${ }^{4}$ Center for Respiratory Diseases China-Japan Friendship Hospital, Beijing, P. R. China

${ }^{5}$ WHO Collaborating Centre for Tobacco Cessation and

Respiratory Diseases Prevention, Beijing, P. R. China

${ }^{6}$ Tobacco Medicine and Tobacco Cessation Center, China-Japan Friendship Hospital, Beijing, P.

R. China

${ }^{7}$ National Clinical Research

Center for Respiratory Diseases,

Beijing, P. R. China

\section{Correspondence to}

Professor Yi Zhou, Center

for Social Research, Peking

University, Beijing 100871, P. R.

China; yizhou@pku.edu.cn

Received 15 March 2018

Revised 23 June 2018

Accepted 30 June 2018

Published Online First

5 September 2018

\section{ABSTRACT}

Background Due to the sustained increases in life expectancy over the past half century, the elderly today will receive supports from their children for a longer period than ever before. Therefore, understanding the spillover effects of children's socioeconomic status on parents' health becomes increasingly important for both scholars and policy makers.

Methods The Ordinary Least Squares regression is applied to the China Health and Retirement Longitudinal Study 2011, a national representative dataset including approximately 10000 households and 17600 middleaged and elderly respondents. The Sobel test is used to examine the mediation role of social integration.

Results The elderly who have a cadre child reported better health (coefficient $=0.1347 ; 95 \% \mathrm{Cl} 0.067$ to 0.202 ), had fewer activities of daily living (ADLs) limitations (coefficient $=-0.1289 ; 95 \% \mathrm{Cl}-0.216$ to -0.042 ) and were more socially integrated (coefficient $=0.2321 ; 95 \% \mathrm{Cl} 0.103$ to 0.361 ). Such effects are mainly driven by the parents of higher-ranking cadres. For the parents of higher ranking cadres, the Sobel test suggests that $12.6 \%$ of the total effects on self-reported health and $21.9 \%$ of the total effects on $A D L$ limitations are mediated by the increase in parents' social integration.

Conclusion The findings suggest positive spillover effects of children's political status on parents' health. The benefits of having a cadre child are at least equivalent to the rural-urban gap in health and even stronger for the parents of higher ranking cadres. One potential explanation for such spillover effects is that a child's political status can improve parents' community involvement and social interactions.

\section{INTRODUCTION}

A large number of studies have shown that the benefits of high socioeconomic status (SES) on health can spill over to other family members, but more than $95 \%$ of previous studies focused only on the transmission from parents to children. ${ }^{1-3}$ The other way, from children to parents, is still understudied. ${ }^{4}$ Until recently, the association between children's education and parents' health has been investigated by only a few studies, most of which find significantly positive correlations ${ }^{5-8}$ with the exception of one Swedish study. ${ }^{9}$ However, the upward intergenerational transmissions of the other dimensions (eg, occupation and social capital) of SES on physical health are almost untouched by researchers.

Because of the sustained increase in life expectancy in the past half century, the spillover effects from adult children to elderly parents become increasingly important both for scholars and policy makers. For example, the life expectancy at age 60 years in China increased from 11.1 years in 1965 to 19.6 years in 2015 . The elderly today on average receive supports from their children for a longer period than ever before.

Political status is one dimension of social capital and it is especially of value in developing countries. As an old Chinese saying goes: 'when a man gets to the top, all friends and relations get there with him'. In China, political status is traditionally considered as family-owned capital rather than as a personal achievement. On the other side, the recruitment of government employees in China is extremely competitive, as it is in many other countries such as UK, Canada and the USA. Since the enforcement of the Civil Servant Law in 2006, all applicants have to pass an open written examination and several rounds of interview to get a position in the government. There are 12 administrative ranks in the bureaucratic system of Chinese government. A high level cadre typically has more power than a low level one.

A number of studies have shown that people are rewarded for their relationships with a government cadre. $^{10-12}$ For example, having a cadre parent is associated with a $15 \%$ premium in the first job offer salary among recent college graduates in China. ${ }^{13}$ The next question is, besides economic benefits, does kinship with a government cadre also improve health? A recent study shows that political connection has a positive effect on cognitive functioning. ${ }^{14}$ To our knowledge, this work is one of the earliest studies investigating the spillover effects of children's political status on parents' physical health.

This study also further explores the mechanisms generating such effects. As shown in figure 1 , we propose two possible channels: monetary transfer from children and parents' social integration. Government employees typically receive a stable monthly salary and thus they are more likely to provide economic supports to parents on a regular basis, and the amount of economic resources has been confirmed as an important determinant of an elderly person's health. ${ }^{15} 16$

Social integration is also a potential pathway for spillover effects. A recent branch of literature suggests that social integration plays an important role in determining health. ${ }^{17-22}$ We expect that the parents of cadre children should be more socially integrated than others. On one side, with the halo of a child's political status, parents would be more comfortable and more confident in daily interactions. On the other side, having a cadre child also creates incentives for relatives and neighbours to 


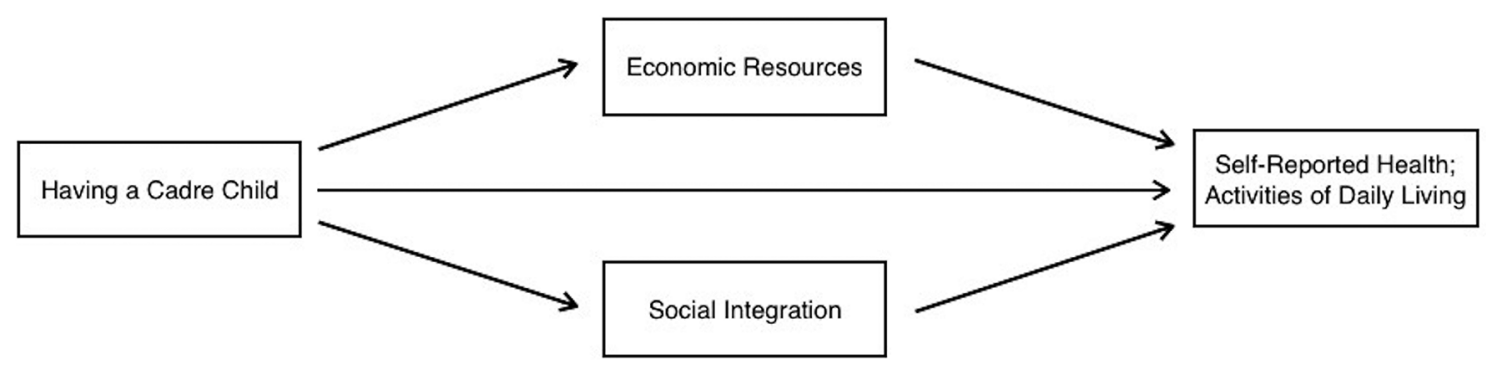

Figure 1 The theoretical framework.

enhance relationships with them, because being tied with people of high political status is beneficial in China. ${ }^{11} 12$

The spillover effects also depend on the administrative rank of cadre children. They should be stronger for the parents of higher ranking cadres than for the parents of lower ranking cadres. Higher ranking cadres tend to earn higher wages and control more political power and have typically been working in the government for a longer period; thus, their parents have had longer exposure to their political status.

With the China Health and Retirement Longitudinal Study (CHARLS) data, this study uses Ordinary Least Squares (OLS) regressions to explore how children's political status is associated with the physical health of elderly parents.

\section{METHODS \\ Data}

The sample is from the CHARLS, a publicly available survey data managed by Peking University. As a sister study of the Health and Retirement Study, the CHARLS programme has collected a nationally representative sample of Chinese residents aged 45 years and older. ${ }^{23}$ When an individual who is 45 years or older is sampled, his or her spouse is automatically included without regard to age. The sample includes approximately 10000 households and 17352 respondents in 27 provinces. As the baseline survey, the 2011 wave of CHARLS has best national representativeness, while the following waves start to suffer from mortality selection. That is, the dropouts in following waves are not random, and replenishment with new respondents may not fully compensate for the loss of representativeness. Thus, we conduct our cross-sectional regressions with the 2011 wave sample. We also repeat our analyses with the 2013 wave sample and get almost identical results.

\section{The measurements of outcomes}

Health is measured with two indicators: self-reported health (SRH) and activities of daily living limitations (ADL limitations). Compared with ADL limitations, SRH is more comprehensive and also more subjective. ${ }^{24} 25$ In the survey, respondents were asked, 'How would rate your health? Would you say your health is very good, good, fair, poor, or very poor?' We transformed the five options into numeric scores ranging from 1 ('very poor') to 5 ('very good') to get the SRH indicator. The ADL limitations indicator is used to capture overall physical function. Respondents were asked whether they had difficulty in performing a specific daily activity because of a health problem. If the answer is yes, then this term will be scored 1 . We construct the ADL indicator limitations by summing up scores in all 10 questions related to the functioning of daily activities (including dressing, bathing, eating, getting into or out of bed, using the toilet, controlling urination and defecation, doing house chores, preparing for hot meals, shopping for groceries and managing money).

\section{The measurement of child's political status}

The child's political status is measured by whether the child is a government employee and at what rank. The proportion of the elderly that have at least one child working as a government cadre in our sample is $4.9 \%$. Following the approach of a political study, ${ }^{26}$ we further classify all cadre children into two categories: lower ranking ('Ke' level and below) and higher ranking ('Chu' level and above). 'Ke' and 'Chu' officials, who represent the majority of the Chinese bureaucracy, often hold specific power locally. If a respondent has more than one cadre child, we use the category of the highest ranking one.

\section{The measurement of social integration}

The indicator of social integration is a weighted sum of a respondent's answers about his or her involvements and frequencies of the following five social activities in the past month: (1) interacted with friends; (2) played Mah-jong, chess or cards or went to a community club; (3) provided help to family, friends or neighbours who do not live with you and who did not pay you for help; (4) went to a sport, social or other kind of club; and (5) took part in a community-related organisation. The answer for each activity is transformed into a value ranging from 0 to 3 , according to its frequency in the past month (none $=0$; not regularly $=1$; almost every week $=2$; almost daily $=3$ ). Therefore, the aggregated indicator can range from 0 to 15 . The highest value of this variable in our sample is 12 .

\section{Other covariates}

We control for several variables of individual characteristics such as age, gender, marital status, education in years, the number of living children, and the number of chronic diseases. There are four categories for marital status: married or cohabiting, unmarried, divorced and widowed. About $87 \%$ of the sample are married or cohabiting, and $10.6 \%$ are widowed. Individuals in the status of 'unmarried' or 'divorced' are relatively rare. Thus, we use 'married or cohabiting' as the reference group and construct dummy variables for the other three. The respondents were also asked about whether they had been diagnosed by a doctor as having a chronic disease. There are 14 chronic diseases, such as hypertension, diabetes and cancer on the list of the questionnaire. A couple of variables of community characteristics, including whether the community in located in a plain area and whether the roads in the community are paved, are included in our regressions.

A variable of 'local-elite' status is constructed to exclude the influence of parent's own career success. More specifically, an elderly parent is counted as local elite if he or she satisfies any of the following criteria: former government employee, former village head, former manager in a firm and self-employed entrepreneur with annual income above the average of self-employed group. To examine the effects from the channel of economic 
Table 1 Variable definition and statistical summary

\begin{tabular}{|c|c|c|c|c|}
\hline Variable & Definition & Mean & Std. & Obs. \\
\hline Self-reported health & Very good=5; good=4; fair $=3$; poor $=2$; very poor $=1$. & 2.999 & 0.902 & 13486 \\
\hline $\begin{array}{l}\text { Activities of daily living } \\
\text { limitations }\end{array}$ & The number of ADL limitation problems (from 0 to 10 ). & 0.367 & 1.260 & 17352 \\
\hline Cadre child & $\begin{array}{l}\text { If the respondent has at least one child working as a cadre in the government }=1 \text {; } \\
\text { otherwise }=0 \text {. }\end{array}$ & 0.049 & - & 17352 \\
\hline Lower ranking & If the cadre child holds an administrative rank of ' $\mathrm{Ke}^{\prime}$ level or below=1; otherwise $=0$. & 0.026 & - & 17352 \\
\hline Higher ranking & If the cadre child holds an administrative rank of 'Chu' level or above $=1$; otherwise $=0$. & 0.024 & - & 17352 \\
\hline Professional child & $\begin{array}{l}\text { If the respondent has at least one child holding a professional title without administrative } \\
\text { rank }=1 \text {; otherwise }=0 \text {. }\end{array}$ & 0.012 & 0.291 & 17352 \\
\hline Manager child & $\begin{array}{l}\text { If the respondent has at least one child who works as manager but does not have } \\
\text { administrative rank in his or her work units }=1 \text {; otherwise }=0 \text {. }\end{array}$ & 0.093 & 0.291 & 17352 \\
\hline Social integration & The frequency of social interactions. & 1.287 & 1.790 & 17352 \\
\hline Age & The age of elderly respondent in years. & 59.047 & 10.127 & 17321 \\
\hline Age square & The square of age. & - & - & 17321 \\
\hline Female & If the elderly respondent is female $=1$; If male $=0$. & 0.479 & - & 17340 \\
\hline Unmarried & If the elderly respondent is unmarried $=1$; otherwise $=0$. & 0.009 & - & 17352 \\
\hline Divorced & If the elderly respondent is divorced $=1$; otherwise $=0$. & 0.013 & & \\
\hline Widowed & If the elderly respondent is widowed $=1$; otherwise $=0$. & 0.106 & & \\
\hline Education & The education of the elderly respondent in years. & 5.293 & 4.339 & 17322 \\
\hline Number of living children & The number of living children of the elderly respondent. & 2.643 & 1.448 & 17352 \\
\hline Depression & The number of depressive symptoms (from 0 to 8 ). & 2.268 & 1.938 & 17352 \\
\hline Chronic diseases & $\begin{array}{l}\text { The number of chronic diseases that the elderly respondent has been diagnosed with } \\
\text { (from } 0 \text { to 14). }\end{array}$ & 1.362 & 1.393 & 17352 \\
\hline Log of financial assets & The logarithm of family financial assets. & 4.003 & 5.666 & 16416 \\
\hline Local elite & $\begin{array}{l}\text { If the elderly respondent was former government employee, former village head, former } \\
\text { manager in firm or self-employed entrepreneur with an annual income above the average } \\
\text { level of the self-employed group }=1 \text {; otherwise }=0 \text {. }\end{array}$ & 0.050 & 0.219 & 17352 \\
\hline Rural & If the elderly respondent is living in the rural (yes=1). & 0.767 & - & 17352 \\
\hline Plain area & Whether the community is in a plain area (yes=1). & 0.958 & - & 17318 \\
\hline Paved road & Whether the roads in community are paved (yes $=1$ ). & 0.447 & - & 17352 \\
\hline
\end{tabular}

resources, we include the amount of monetary transfer from children in our regression models.

To check whether the effects are from political capital or other dimensions of occupational status, we also conduct dummy variables indicating whether an elderly person has a child working as professional or manager without administrative rank. For example, if the respondent has a child who holds a profession title without administrative rank, then the dummy variable 'professional child' equals 1 . Otherwise, it equals 0. Table 1 shows the definition and statistical description of each variable.

\section{Data analysis}

The method used for data analyses is the OLS regression. The specification of our empirical model is:

$$
\mathrm{SRH}_{i}\left(\text { or } A D L L_{i}\right)=\beta_{0}+\beta_{1} \text { Cadre } \text { Child }_{i}+\gamma X_{i}+\varepsilon_{i} .
$$

The dependent variable is either the self-reported health $S R H_{i}$ or the indicator of ADL limitations $A D L L_{i}$. The explanatory variable Cadre Child $i$ is a dummy indicating whether the respondent has a cadre child or not (if yes $=1$; otherwise $=0$ ). $X_{i}$ are a variety of other covariates. We also perform regressions with the subsamples separately to examine the difference between higher ranking and lower ranking cadre children. We use the statistical software STATA V.13.0 (StataCorp, 2012) to conduct regression analyses.
To examine whether promoting social integration is among the mediators of the spillover effects, we change the dependent variable and run the following regression:

$$
S I_{i}=\beta_{0}+\beta_{1} \text { Cadre Child } i+\gamma X_{i}+\varepsilon_{i}
$$

where $S I_{i}$ is respondent's social integration.

The age distribution of elderly parents is different across groups. For example, the parents of higher ranking cadres are older than the parents of lower ranking cadres and also other elderly parents. In such case, the estimation could be sensitive to minor changes in the specification because conventional regression methods heavily rely on extrapolation. ${ }^{27}$ In order to avoid the potential bias caused by invalid extrapolation, a matching approach based on age is employed. That is, we construct control groups by subsampling from the sample of parents who do not have any cadre children. The subsampling weight $\mathrm{w}$ (a) is calculated as follows:

$$
\mathrm{w}(\mathrm{a})=\operatorname{Pr}\left[\text { age }_{i}=\mathrm{al} C C_{i}^{k}=1\right] .
$$

If an elderly parent $i$ has a $k$ type cadre child, then $C C_{i}^{k}=1$, otherwise $C C_{i}^{k}=0$. Here $k$ can be $h$ (higher ranking cadre) or $l$ (lower ranking cadre). We conduct regression analyses with the matching sample for robustness.

We then perform a Sobel test to estimate how much of the spillover effect is mediated through the channel of social integration. The Sobel test is widely used for investigating whether 
Table 2 Estimates of OLS regression for having a cadre child on health: full sample

\begin{tabular}{|c|c|c|}
\hline & (1) & (2) \\
\hline & Self-reported health & ADL limitations \\
\hline & Coefficient $(95 \% \mathrm{Cl})$ & Coefficient $(95 \% \mathrm{Cl})$ \\
\hline Local elite & $0.1848^{* * *}(0.114$ to 0.255$)$ & $-0.0040(-0.091$ to 0.083$)$ \\
\hline Female (yes $=1$ ) & $0.0288^{*}(-0.002$ to 0.060$)$ & $0.0186(-0.021$ to 0.059$)$ \\
\hline Age in years & $0.0087(-0.005$ to 0.022$)$ & $-0.1689^{* * *}(-0.187$ to -0.151$)$ \\
\hline Unmarried (yes $=1$ ) & $-0.1074(-0.264$ to 0.049$)$ & $0.1538(-0.041$ to 0.348$)$ \\
\hline Divorced (yes=1) & $0.0224(-0.104$ to 0.149$)$ & $-0.0053(-0.167$ to 0.156$)$ \\
\hline Widowed (yes=1) & $0.1057^{* * *}(0.057$ to 0.155$)$ & $-0.0682^{* *}(-0.134$ to -0.002$)$ \\
\hline Education in years & $0.0123^{* * *}(0.008$ to 0.016$)$ & $-0.0157^{* * *}(-0.021$ to -0.010$)$ \\
\hline The number of chronic diseases & $-0.2217^{* * *}(-0.232$ to -0.211$)$ & $0.1366^{* * *}$ (0.123 to 0.150$)$ \\
\hline Money from children & $0.0210(-0.014$ to 0.056$)$ & $0.0273(-0.021$ to 0.075$)$ \\
\hline Living in plain area (yes=1) & $0.0042(-0.014$ to 0.022$)$ & $-0.0125(-0.036$ to 0.011$)$ \\
\hline Paved road (yes $=1$ ) & $-0.0072(-0.029$ to 0.015$)$ & $0.0061(-0.023$ to 0.035$)$ \\
\hline Rural (yes $=1$ ) & $-0.1175^{* * *}(-0.158$ to -0.077$)$ & $0.0657^{* *}(0.013$ to 0.118$)$ \\
\hline Constant & $3.2579^{* * *}(2.836$ to 3.680$)$ & $4.5044^{* * *}(3.941$ to 5.067$)$ \\
\hline Province dummies & Yes & Yes \\
\hline Observations & 12540 & 16131 \\
\hline R-squared & 0.244 & 0.137 \\
\hline
\end{tabular}

$95 \% \mathrm{Cl}$ shown in parentheses.

${ }^{* * *} P<0.01,{ }^{* *} p<0.05,{ }^{*} p<0.1$

OLS, Ordinary Least Squares.

one factor is among the mediating mechanisms that translate a stimulus into a response. ${ }^{28} 29$ It is basically a specialised t-test used for examining whether the effect of the independent variable has a statistically significant reduction after including the mediator in the model.

In the introduction, we also hypothesise that economic resources could be among the channels mediating the spillover effects, but the correlation between the monetary transfer from children and elderly parents' health is found to be weak. Moreover, only a small proportion (about 10\%) of the respondents reported that they had received money from children in the past year. This suggests that the monetary transfers from children to parents is either less important in determining health or under-reported in the survey. For example, due to a sense of self-esteem, some parents may not like to report monetary transfer even though they actually have received. Given that the potential sample selection in the reporting of monetary transfer, we do not conduct mediation analysis on this channel but treat it as a control.

\section{RESULTS}

\section{The effects of having a cadre child on health}

Table 2 reports the results of OLS regressions with the full sample. As shown in column 1 , on average, the parents of cadre children report significantly better health. The coefficient of our key explanatory variable is 0.1347 (95\% CI 0.067 to 0.202 ), which suggests that the effect of having a cadre child is even greater than the rural-urban gap (coefficient $=-0.1175 ; 95 \%$ CI -0.158 to -0.077$)$.
From column 2, we can see that the parents of cadre children also have fewer ADL limitations (coefficient $=-0.1289 ; 95 \% \mathrm{CI}$ -0.216 to -0.042 ). At the same time, the coefficient of the variable 'money from children' is not statistically significant in column 1 as well as in column 2 .

The coefficients of control variables are similar to those in peer studies ${ }^{30-32}$ : a wealthy urban-educated respondent without depression and chronic diseases has better health than others. The coefficients of 'unmarrried' and 'divorced' dummies are not statistically significant partially because the proportions of 'unmarried', and 'divorced' respondents are only $0.9 \%$ and $1.3 \%$ correspondingly. A 'local-elite' who was more successful in their career than were their peers also tends to be healthier.

\section{The role of cadre child's administrative rank}

To examine the role of a cadre child's administrative rank, we reconduct the regressions above with two subsamples separately and present results in table 3 . The higher ranking subsample excludes the parents of lower ranking cadres, and the lower ranking subsample excludes the parents of higher ranking cadres. A stronger spillover effect was found on the SRH of higher ranking cadres' parents (coefficient $=0.1558$; 95\% CI 0.056 to 0.256 ); about $50 \%$ higher than the effect of having a lower ranking cadre (coefficient $=0.1109$; 95\% CI 0.019 to 0.203 ). The pattern is similar if we replace the independent variable with the variable of ADL limitations. The coefficient of having a higher ranking cadre is -0.2506 (95\% CI -0.377 to $-0.124)$, while the coefficient of having a lower ranking cadre is 
Table 3 Estimates of OLS regression for having a cadre child on health: by administrative rank

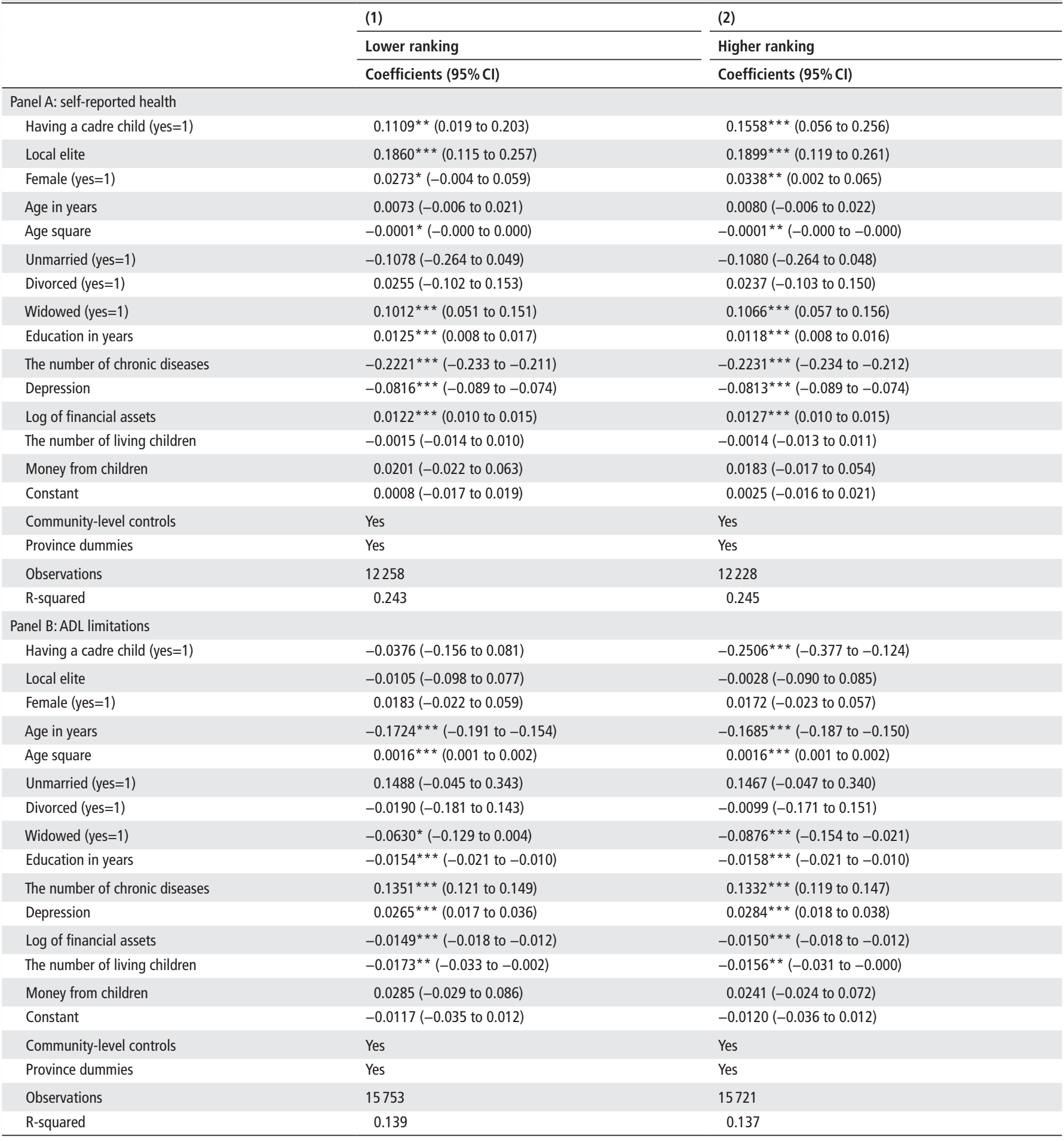

$95 \% \mathrm{Cl}$ shown in parentheses.

${ }^{* * *} p<0.01,{ }^{* *} p<0.05,{ }^{*} p<0.1$.

$A D L$, activities of daily living; OLS, Ordinary Least Squares.

much lower and statistically insignificant (coefficient $=-0.0376$; $95 \%$ CI -0.156 to 0.081 ).

\section{Social integration: a potential mediator}

The estimates of OLS regression for having a cadre child on social integration are reported in table 4 . According to column 1 , parents of government cadres are more socially integrated than other elderly parents (coefficient $=0.2321 ; 95 \%$ CI 0.103 to 0.361 ), and the positive spillover effects are stronger and more significant for the parents of higher ranking cadres (coefficient $=0.4091 ; 95 \% \mathrm{CI}$ 0.221 to 0.597 ) than for the parents of lower ranking cadres (coefficient $=0.0768 ; 95 \% \mathrm{CI}-0.099$ to 0.252 ). 
Table 4 Estimates of OLS regression for having a cadre child on social integration

\begin{tabular}{|c|c|c|c|}
\hline Independent variable & (1) & (2) & (3) \\
\hline \multirow[t]{2}{*}{ Social integration } & Full sample & Lower ranking & Higher ranking \\
\hline & Coefficients (95\% Cl) & Coefficients $(95 \% \mathrm{Cl})$ & Coefficients (95\% Cl) \\
\hline Local elite & $0.1857^{* * *}(0.057$ to 0.314$)$ & $0.1694^{* *}(0.040$ to 0.299$)$ & $0.2054^{* * *}(0.076$ to 0.335$)$ \\
\hline Female (yes=1) & $-0.1122^{* * *}(-0.172$ to -0.053$)$ & $-0.1077^{* * *}(-0.167$ to -0.048$)$ & $-0.1137^{* * *}(-0.174$ to -0.054$)$ \\
\hline Age in years & $0.0013(-0.025$ to 0.028$)$ & $-0.0022(-0.029$ to 0.025$)$ & $-0.0052(-0.032$ to 0.022$)$ \\
\hline Unmarried (yes=1) & $-0.1381(-0.426$ to 0.150$)$ & $-0.1332(-0.420$ to 0.154$)$ & $-0.1462(-0.434$ to 0.141$)$ \\
\hline Divorced (yes=1) & $-0.0876(-0.327$ to 0.152$)$ & $-0.0866(-0.326$ to 0.153$)$ & $-0.0988(-0.338$ to 0.141$)$ \\
\hline Widowed (yes=1) & $0.1919^{* * * *}$ (0.094 to 0.289$)$ & $0.1914^{* * *}(0.093$ to 0.290$)$ & $0.1985^{* * *}(0.100$ to 0.297$)$ \\
\hline Education in years & $0.0332^{* * * *}(0.025$ to 0.041$)$ & $0.0323^{* * *}(0.024$ to 0.040$)$ & $0.0330^{* * *}(0.025$ to 0.041$)$ \\
\hline The number of chronic diseases & $0.0199^{*}(-0.001$ to 0.040$)$ & $0.0205^{*}(-0.000$ to 0.041$)$ & $0.0189^{*}(-0.002$ to 0.040$)$ \\
\hline Money from children & $0.1992^{* * *}(0.128$ to 0.270$)$ & $0.2030^{* * *}(0.118$ to 0.288$)$ & $0.1996^{* * *}(0.128$ to 0.271$)$ \\
\hline Living in plain area $($ yes $=1$ ) & $-0.0351^{* *}(-0.070$ to -0.000$)$ & $-0.0323^{*}(-0.067$ to 0.003$)$ & $-0.0341^{*}(-0.069$ to 0.001$)$ \\
\hline Paved road (yes $=1$ ) & $-0.0381^{*}(-0.082$ to 0.005$)$ & $-0.0366(-0.080$ to 0.007$)$ & $-0.0314(-0.075$ to 0.013$)$ \\
\hline Rural (yes=1) & $-0.4020^{* * *}(-0.480$ to -0.324$)$ & $-0.3972^{* * *}(-0.476$ to -0.318$)$ & $-0.3801^{* * *}(-0.459$ to -0.301$)$ \\
\hline Constant & $1.3540^{* * *}(0.519$ to 2.189$)$ & $1.4727^{* * *}(0.633$ to 2.313$)$ & $1.5135^{* * *}(0.672$ to 2.355$)$ \\
\hline Province dummies & Yes & Yes & Yes \\
\hline Observations & 16131 & 15753 & 15721 \\
\hline R-squared & 0.073 & 0.070 & 0.074 \\
\hline
\end{tabular}

$95 \% \mathrm{Cl}$ shown in parentheses.

${ }^{* * *} p<0.01,{ }^{* *} p<0.05,{ }^{*} p<0.1$

\section{Regression analyses and Sobel test with matching subsamples}

Because the age distribution is significantly different across groups, we employ a matching strategy to construct suitable control groups. That is, we draw 4000 respondents randomly from those who do not have cadre child, and the subsampling weights are based on the age distribution of the parents of lower ranking cadres. A similar process is also conducted for the parents of higher ranking cadres. We compare the age distribution of each matching subsample with the actual age distribution of corresponding treatment group in figure 2 .

Table 5 shows the estimates of OLS regression with the new matching subsamples. Compared with the original regressions, the regressions with matching samples have higher R-squared values but smaller and less significant coefficients. The differences in coefficients between original and matching regressions are relatively larger for the lower ranking subsample. However, in general, the patterns of the results do not change. It suggests that our findings are not that sensitive to minor changes in model specification.

We conduct Sobel tests on lower ranking and higher ranking subsamples respectively and report the results in table 5 . Social integration is confirmed among the mediating factors for the spillover effects only in the higher ranking sample (SRH: $z$-score $=2.659$; ADL limitations: $z$-score $=-3.437$ ) but not in the lower ranking sample (SRH: $z$-score $=-0.536$; ADL limitations: $\mathrm{z}$-score $=-0.498$ ). For the higher ranking sample, about $12.6 \%$ of the spillover effects on SRH and $21.9 \%$ of the spillover effects on ADL limitations are mediated through the channel of social integration.

\section{DISCUSSION}

This study joins the recent debate on whether there exists an intergenerational transmission of health from children to parents. Most previous studies have found positive spillover effects. However, a very recent study in Sweden adopts the instrumental variable approach to identify the causal effects of children's schooling on parents' longevity and found no statistically significant change. ${ }^{9}$ This raises a question why the spillover effects from children to parents are found only in some countries but not in others. A possible explanation is that the strength of such spillover effects also depends on cultural context and institutional arrangements.

For example, we expect that the spillover effects should be more influential in China than in Sweden. First, filial piety is considered one of the fundamental ethics in Chinese societies, and children are expected to take on the responsibility of caring for their parents. ${ }^{33}$ Second, the elderly care industries are less developed, and the welfare system is not sufficiently generous in China. In the short term, neither market nor state is able to substitute for the role of family in caring for the elderly.

Our estimates can be biased due to problems of omitted variables, endogeneity or sample selection. For example, it is possible that political status does not matter, and the beneficial spillover effect is caused by some other characteristics of cadre children. To take this possibility into account, we examine whether the parents of professional children and manager children have better outcomes as well. As shown in table 6, the coefficients are only statistically significant for the parents of cadre children.

Moreover, about $23 \%$ of the respondents in CHARLS did not answer the question on SRH. This is partially because 

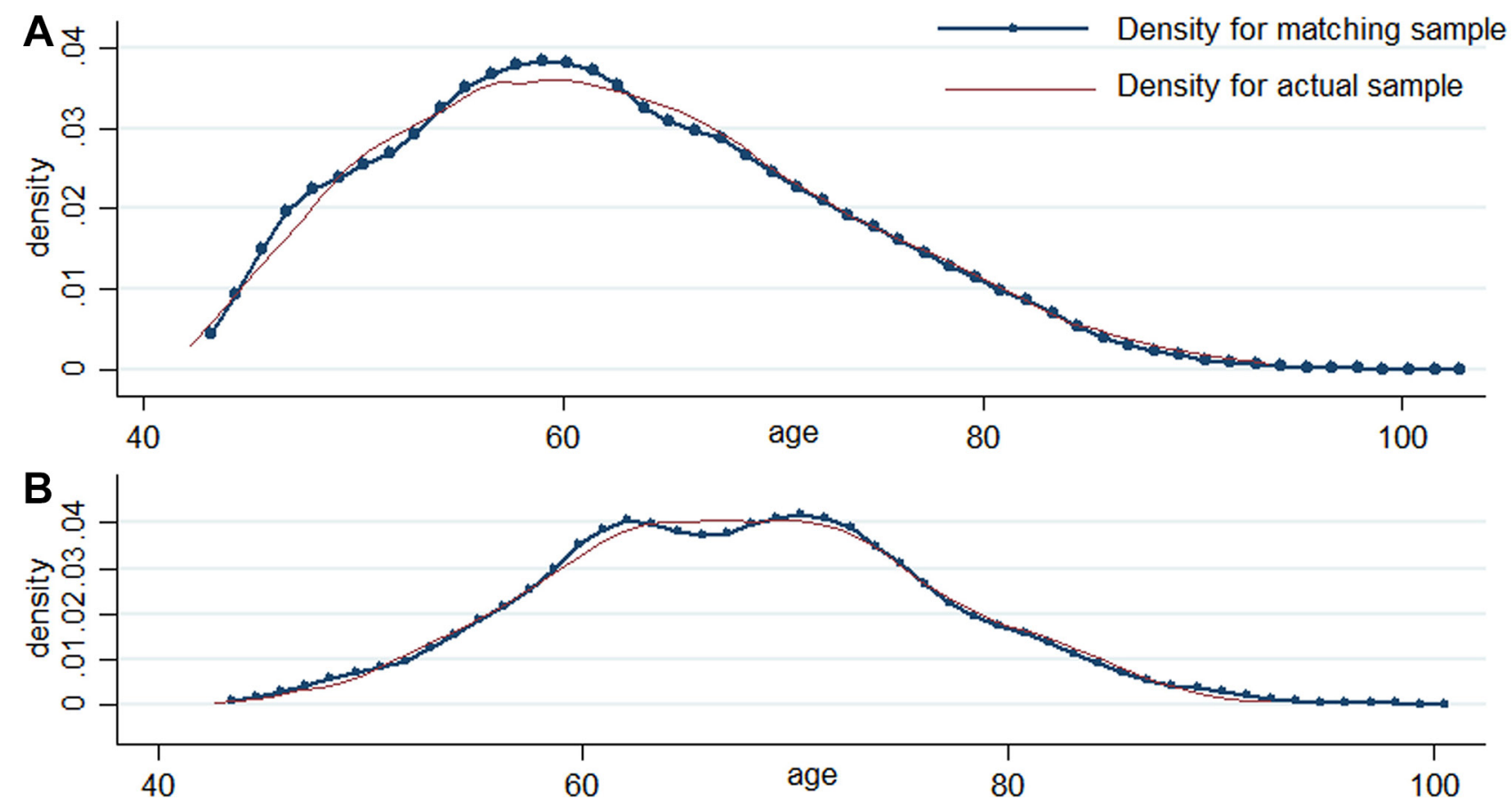

Figure 2 The age distributions of the parents of cadres and corresponding matching sample.

some questionnaires were answered by other individuals in the family who were not able to answer questions related to the respondent's subjective feeling. An imputation strategy is used to examine how much our estimates could be biased by potential sample selection due to these missing values. That is, we impute the missing values with answers randomly drawn

\section{Table 5 Estimates of OLS regression with matching subsamples}

\begin{tabular}{|c|c|c|c|c|c|c|}
\hline & (1) & (2) & (3) & (4) & (5) & (6) \\
\hline & \multicolumn{2}{|l|}{ Self-reported health } & \multicolumn{2}{|l|}{ ADL limitations } & \multicolumn{2}{|l|}{ Social integration } \\
\hline & Original & Matching & Original & Matching & Original & Matching \\
\hline \multicolumn{7}{|l|}{ Panel A: lower ranking } \\
\hline Coefficient $(95 \% \mathrm{Cl})$ & $\begin{array}{l}0.1109^{* *}(0.019 \text { to } \\
0.203)\end{array}$ & $\begin{array}{l}0.0836^{*}(-0.012 \text { to } \\
0.179)\end{array}$ & $\begin{array}{l}-0.0376(-0.156 \text { to } \\
0.081)\end{array}$ & $\begin{array}{l}-0.0353(-0.170 \text { to } \\
0.099)\end{array}$ & $\begin{array}{l}0.0768(-0.099 \text { to } \\
0.252)\end{array}$ & $\begin{array}{l}0.0495 \text { ( }-0.133 \text { to } \\
0.232)\end{array}$ \\
\hline Other controls & Yes & Yes & Yes & Yes & Yes & Yes \\
\hline Province dummies & Yes & Yes & Yes & Yes & Yes & Yes \\
\hline Observations & 12258 & 3145 & 15753 & 4080 & 15753 & 4080 \\
\hline R-squared & 0.243 & 0.246 & 0.139 & 0.165 & 0.069 & 0.101 \\
\hline \multicolumn{7}{|c|}{ Sobel test of mediation for social integration } \\
\hline & Total effect & Direct effect & Indirect effect & \multicolumn{3}{|c|}{ Proportion of total effect that is mediated } \\
\hline Self-reported health & $0.088^{*}$ & $0.09^{*}$ & -0.002 & $-2.7 \%$ & & \\
\hline ADL limitations & -0.038 & -0.035 & -0.004 & $9.6 \%$ & & \\
\hline \multicolumn{7}{|l|}{ Panel B: higher ranking } \\
\hline Coefficient (95\% Cl) & $\begin{array}{l}0.1558^{* * *} \text { ( } 0.056 \text { to } \\
0.256)\end{array}$ & $\begin{array}{l}0.1466^{* * *}(0.042 \text { to } \\
0.251)\end{array}$ & $\begin{array}{l}-0.2506^{* * *}(-0.377 \\
\text { to }-0.124)\end{array}$ & $\begin{array}{l}-0.1829 * *(-0.347 \text { to } \\
-0.019)\end{array}$ & $\begin{array}{l}0.4091 * * * *(0.221 \text { to } \\
0.597)\end{array}$ & $\begin{array}{l}0.3797^{* * *} \text { (0.181 to } \\
0.579)\end{array}$ \\
\hline Other controls & Yes & Yes & Yes & Yes & Yes & Yes \\
\hline Province dummies & Yes & Yes & Yes & Yes & Yes & Yes \\
\hline Observations & 12228 & 3145 & 15721 & 4080 & 15721 & 4080 \\
\hline R-squared & 0.245 & 0.246 & 0.137 & 0.165 & 0.074 & 0.101 \\
\hline \multicolumn{7}{|c|}{ Sobel test of mediation for social integration } \\
\hline & Total effect & Direct effect & Indirect effect & \multicolumn{3}{|c|}{ Proportion of total effect that is mediated } \\
\hline Self-reported health & $0.147^{* * *}$ & $0.128^{* *}$ & $0.019 * * *$ & \multicolumn{3}{|l|}{$12.6 \%$} \\
\hline ADL limitations & $-0.19 * *$ & $-0.148^{*}$ & $-0.041 * * *$ & \multicolumn{3}{|l|}{$21.9 \%$} \\
\hline
\end{tabular}

$95 \% \mathrm{Cl}$ shown in parentheses.

${ }^{* * *} p<0.01,{ }^{* *} p<0.05,{ }^{*} p<0.1$.

$A D L$, activities of daily living; OLS, Ordinary Least Squares. 
Table 6 Estimates of OLS regression for having a professional child or a manager child

(1) (2) (3)

\begin{tabular}{|c|c|c|c|}
\hline \multicolumn{4}{|l|}{ Panel A: self-reported health } \\
\hline Having a cadre child (yes=1), $(95 \% \mathrm{Cl})$ & $0.1347^{* * *}(0.067$ to 0.202$)$ & & \\
\hline Having a professional child (yes $=1$ ) & & $0.0554(-0.080$ to 0.210$)$ & \\
\hline Having a manager child (yes=1) & & & $0.0284(-0.023$ to 0.080$)$ \\
\hline Other controls & Yes & Yes & Yes \\
\hline Province dummies & Yes & Yes & Yes \\
\hline Observations & 12540 & 12540 & 12540 \\
\hline R-squared & 0.244 & 0.242 & 0.242 \\
\hline \multicolumn{4}{|l|}{ Panel B: ADL limitations } \\
\hline Having a cadre child (yes=1), $(95 \% \mathrm{Cl})$ & $-0.1289^{* * *}(-0.216$ to -0.042$)$ & & \\
\hline Having a professional child (yes=1), (95\% Cl) & & $-0.0529(-0.239$ to 0.134$)$ & \\
\hline Having a manager child (yes=1), $(95 \% \mathrm{Cl})$ & & & $-0.0470(-0.118$ to 0.024$)$ \\
\hline Other controls & Yes & Yes & Yes \\
\hline Province dummies & Yes & Yes & Yes \\
\hline Observations & 16131 & 16131 & 16131 \\
\hline R-squared & 0.137 & 0.136 & 0.136 \\
\hline
\end{tabular}

$95 \% \mathrm{Cl}$ in parentheses.

${ }^{* * *} P<0.01,{ }^{* *} p<0.05,{ }^{*} p<0.1$

$A D L$, activities of daily living; $O L S$, Ordinary Least Squares.

Table 7 Estimates of OLS regression on self-reported health with imputed data

\begin{tabular}{|c|c|c|c|c|c|c|}
\hline \multirow[b]{2}{*}{ Independent variable: } & (1) & \multirow[t]{2}{*}{ (2) } & (3) & \multirow[t]{2}{*}{ (4) } & (5) & \multirow[t]{2}{*}{ (6) } \\
\hline & All & & Lower ranking & & Higher ranking & \\
\hline Self-reported health & Original & Imputed data & Original & Imputed data & Original & Imputed \\
\hline Having a cadre child (yes=1), $(95 \% \mathrm{Cl})$ & $\begin{array}{l}0.1347^{* * *}(0.067 \text { to } \\
0.202)\end{array}$ & $\begin{array}{l}0.0963^{* * *}(0.029 \text { to } \\
0.164)\end{array}$ & $\begin{array}{l}0.1109^{* *} \text { (0.019 to } \\
0.203)\end{array}$ & $\begin{array}{l}0.0705(-0.023 \text { to } \\
0.164)\end{array}$ & $\begin{array}{l}0.1558^{* * *}(0.056 \text { to } \\
0.256)\end{array}$ & $\begin{array}{l}0.1225^{* *} \text { ( } 0.023 \text { to } \\
0.222)\end{array}$ \\
\hline Other controls & Yes & Yes & Yes & Yes & Yes & Yes \\
\hline Province dummies & Yes & Yes & Yes & Yes & Yes & Yes \\
\hline Observations & 12540 & 16166 & 12258 & 15788 & 12228 & 15756 \\
\hline
\end{tabular}

Standard errors in parentheses.

${ }^{* * *} \mathrm{p}<0.01,{ }^{* *} \mathrm{p}<0.05,{ }^{*} \mathrm{p}<0.1$.

$A D L$, activities of daily living; OLS, Ordinary Least Squares.

from the subsample who have answered this question and add a dummy variable indicating whether the observation answered the question of SRH into regressions. As shown in table 7, the coefficients remain statistically significant though coefficients become smaller compared with the estimates with the original data.

This study still has some limitations that could be covered by further studies. First, because there is almost no temporal variation of children's political status in the short term, we only use cross-sectional information for estimation. After the CHARLS has conducted more follow-up surveys, it will be possible to perform a longitudinal study and get more convincing findings. Second, the full picture of the mechanism generating the spillover effects is still not clear. We find that social integration is one part of the mechanism but monetary transfer is not. However, the channel of social integration only mediates at most one-fifth of the total effects. Further studies could explore other parts of the mechanism. Third, our study supports the existence of the upward intergenerational transmission of health. In this case, how does it contribute to the persistent stratification of health in later life? This is a question that has strong policy implications but is not easy to answer.

\section{What is already known on this subject}

- More than $95 \%$ of previous studies on intergenerational transmission only investigate the spillover effects from parents to children. The other way, which transmits from children to parents, is understudied. Some scholars have more recently begun to investigate the effects of adult children's schooling on parents' health, but a conclusive answer has not yet been found.

\section{What this study adds}

This is the first study to investigate the association between children's political status and parents' physical health. Using a nationally representative sample of 17500 middle-aged and old individuals in China, we find positive spillover effects from children to parents. We propose that promoting social integration is among the mechanisms generating such spillover effects, and then confirm the role of social integration mediation with a Sobel test. 


\section{CONCLUSION}

Using the CHARLS data, this study finds that the political status of adult children is positively associated with elderly parents' self-reported health and activities of daily living. Such effects are especially significant for parents of higher-ranking cadres. Further mediation analyses suggest that promoting social integration is among the channels mediating such beneficial spillover effects.

Contributors This study was supervised by YZ. XZ drafted the manuscript. HT collaborated with XZ on analysing and interpreting the data. HT performed the statistical analysis. All authors contributed to the study. This study is financially supported by 'the Fundamental Research Funds for Central Universities'.

Funding The Fundamental Research Funds for Central Universities in China.

Competing interests None declared.

Patient consent Not required.

Provenance and peer review Not commissioned; externally peer reviewed.

\section{REFERENCES}

1 Aizer A, Currie J. The intergenerational transmission of inequality: maternal disadvantage and health at birth. Science 2014;344:856-61.

2 Ahlburg $D$. The intergenerational transmission of health-risk behaviors: adolescent lifestyles and gender moderating effects. American Economic Review 1998;88:265-70.

3 Wickrama KA, Conger RD, Wallace LE, et al. The intergenerational transmission of health-risk behaviors: adolescent lifestyles and gender moderating effects. $J$ Health Soc Behav 1999:40:258-72.

4 De Neve JW, Kawachi I. Spillovers between siblings and from offspring to parents are understudied: A review and future directions for research. Soc Sci Med 2017;183:56-61.

5 Zimmer Z, Martin LG, Ofstedal MB, et al. Education of adult children and mortality of their elderly parents in Taiwan. Demography 2007;44:289-304.

6 Friedman EM, Mare RD. The schooling of offspring and the survival of parents. Demography 2014;51:1271-93.

7 Yahirun JJ, Sheehan CM, Hayward MD. Adult Children's Education and Parents' Functional Limitations in Mexico. Res Aging 2016;38:322-45.

8 De Neve JW, Harling G. Offspring schooling associated with increased parenta survival in rural KwaZulu-Natal, South Africa. Soc Sci Med 2017;176:149-57.

9 Lundborg P, Majlesi K. Intergenerational transmission of human capital: Is it a oneway street? J Health Econ 2018;57:206-20.

10 Zhang X, Li G. Does guanxi matter to nonfarm employment? J Comp Econ 2003;31:315-31.

11 Bian Y. Bringing Strong Ties Back in: Indirect Ties, Network Bridges, and Job Searches in China. Am Sociol Rev 1997;62:366-85.
12 Bian Y, Ang S. Guanxi Networks and Job Mobility in China and Singapore. Social Forces 1997;75:981-1005.

13 Li H, Meng L, Shi X, et al. Does having a cadre parent pay? Evidence from the first job offers of Chinese college graduates. J Dev Econ 2012;99:513-20.

14 Tan H, Guo C, Zhou Y. Cadre Children and Cognitive Function of Parents in China: The Value of Political Connection. Chin Sociol Rev 2017;49:382-406.

15 Wildman J. Income related inequalities in mental health in Great Britain: analysing the causes of health inequality over time. J Health Econ 2003:22:295-312.

16 Ahern J, Galea S. Social context and depression after a disaster: the role of income inequality. J Epidemiol Community Health 2006;60:766-70.

17 Kawachi I, Kennedy BP, Glass R. Social capital and self-rated health: a contextual analysis. Am J Public Health 1999;89:1187-93.

18 Kawachi I. Social capital and community effects on population and individual health. Ann N Y Acad Sci 1999;896:120-30.

19 Rose R. How much does social capital add to individual health? A survey study of Russians. Soc Sci Med 2000;51:1421.

20 Veenstra G, capital S. SES and health: An individual-level analysis. Social Science \& Medicine 2000;50:619-29.

21 Poortinga W. Social capital: an individual or collective resource for health? Soc Sci Med 2006;62:292-302.

22 Kawachi I, Berkman LF. Social ties and mental health. J Urban Health 2001;78:458-67.

23 Zhao Y, Strauss G, Yang J, et al. China Health and Retirement Longitudinal Study 2011-2012 National Baseline Users' Guide. Beijing: National School of Development, Peking University, 2013.

24 Mossey JM, Shapiro E. Self-rated health: a predictor of mortality among the elderly. Am J Public Health 1982;72:800-8.

25 Jürges $H$. True health vs response styles: exploring cross-country differences in selfreported health. Health Econ 2007;16:163-78.

26 Zhou X. Partial Reform and the Chinese Bureaucracy in the Post-Mao Era. Comp Polit Stud 1995;28:440-68.

27 Imbens G. Matching methods in practice. Journal of Human Resources 2015;50:373-420.

28 Sobel ME. Some New Results on Indirect Effects and Their Standard Errors in Covariance Structure Models. Sociol Methodol 1986;16:159-86.

29 MacKinnon DP, Fairchild AJ, Fritz MS. Mediation analysis. Annu Rev Psychol 2007;58:593-614.

30 Yang T, Cao C, Cottrell RR, et al. Second hand smoke exposure in public venues and mental disorder: a representative nationwide study of China. Tob Induc Dis 2015;13:18.

31 Yang T, Yang XY, Yu L, et al. Individual and regional association between socioeconomic status and uncertainty stress, and life stress: a representative nationwide study of China. Int J Equity Health 2017;16:118.

32 Yang T, Li F, Yang X, et al. Smoking patterns and sociodemographic factors associated with tobacco use among Chinese rural male residents: a descriptive analysis. $B M C$ Public Health 2008;8:248.

33 Sereny M. Living arrangements of older adults in china: the interplay among preferences, realities, and health. Res Aging 2011;33:172-204. 